\title{
Influencing Factors of Outpatients' Satisfaction in China a Cross-Sectional Study of 16 Public Tertiary Hospitals
}

\author{
Fangwei Zhou (D) \\ Caiming $\mathrm{Xu}$ \\ Yanxiang Sun \\ Xuehui Meng
}

Humanities and Management School, Zhejiang Chinese Medical University, Hangzhou, Zhejiang Province, People's Republic of China
Correspondence: Xuehui Meng Humanities and Management School of Zhejiang Chinese Medical University, 548\# Binwen Road, Binjiang District, Hangzhou, 31005I, People's Republic of China

$\mathrm{Tel} / \mathrm{Fax}+86$ 57I-86633056

Email mengxuehui@aliyun.com
Purpose: This study aimed to analyze the status of patient satisfaction in outpatients of tertiary hospitals and the factors affecting patient satisfaction, in order to provide a scientific basis for improving patient satisfaction.

Methods: A total of 6480 surveys of outpatients were conducted by a cross-sectional study in 16 tertiary hospitals in the Zhejiang province of China. The main contents of the survey were the basic characteristics of patients. Statistical description, single-factor analysis and binary logistic regression analysis were used to screen influencing factors.

Results: Results of this study showed that the total satisfaction score of outpatients was $87.13 \pm 13.47$, and higher scored factors in the survey factors were nursing level, the convenience of registration and convenience of appointment diagnosis and treatment. The factors with lower scores were treatment effect, environmental sanitation and comfort and other staffs' attitudes. Hospital managers should pay attention to the improvement of treatment level, environmental sanitation and comfort and other staffs' attitudes.

Conclusion: In the process of serving outpatients, doctors should pay more attention to patients who are male, 31-45 years old or over 60 years old, permanent residents, from public institutions, possessed postgraduate education, without medical insurance, and who visiting paediatrics and Chinese medicine hospitals.

Keywords: outpatient satisfaction, tertiary hospitals, patient, influencing factor

\section{Introduction}

Medical and health services are important public utilities that promote people's health and prevent diseases. Patients are the main customers who use these services. With the development of medical and health services, patients' demands are increasing. Patient satisfaction is an important indicator which has been used widely to measure the quality of inpatient and outpatient care. ${ }^{1}$ Patient satisfaction comes from the experience of patients and their families during the process of medical services. It refers to the patients and their families' experience and expectations for the medical service. ${ }^{2}$ With the increasing clarity of patients' understanding of the law and individual rights and Because of the increasing understanding of the law and individual rights, patients' expectations of good quality of diagnosis and treatment are increasing. Moreover, patient satisfaction has become more and more important for the medical and health care service. For hospital managers, it is necessary to understand what factors influence the patient satisfaction. As an entry point, outpatient services could directly affect patients' 
satisfaction. ${ }^{3}$ However, few researches focus on outpatient satisfaction among different types of hospitals. Hence, it is of great significance to research the outpatient satisfaction among different types of tertiary hospitals, especially in developed areas of China where has the largest populations and medical health resources.

Both developing and developed countries currently attached great importance to patient satisfaction research. Compared with developed countries such as the United States with sufficient research and mature experiences, developing countries such as China and India focusing on different research fields due to their national conditions. $^{4,5}$ Existing research showed that researches on patient satisfaction in China started relatively late. ${ }^{3}$ And most of the researches were conducted in a specific hospital or a specific type of hospital. Further research was needed for the satisfaction of outpatients in tertiary hospitals in China. The Chinese government has been committing to the reform of the medical and health service system since 2009. The content of the reform mainly included five aspects: the establishment of a medical security system, a national essential drug system, a primary health care service system, pursuing medical equity of basic public health, and conducting a pilot reform of public hospitals. ${ }^{2,8}$

In addition, it could be seen in the literature in recent years that there were many controversies in the evaluation of patient satisfaction in different countries. The research of Senait and Teshome showed that the assessment of patient satisfaction currently had ambiguous results due to differences between individual factors. ${ }^{9,10}$ Miriam's research showed that the subjectivity of patients will affect the results of satisfaction evaluation. ${ }^{11}$ The abovementioned studies were used to evaluate the satisfaction of specific types of subjects in the hospital environment of different developed and developing countries. Even if the research was conducted under such micro-specific conditions, these documents still showed satisfaction and influence in the conclusion The causal relationship between factors was still controversial. Mukesh's research suggests that although patient satisfaction was controversial, it could already be used as an indicator to measure the quality of health care in hospitals. This research also improved the evaluation of patient satisfaction in Nepalese hospitals based on previous literature. ${ }^{12}$ In order to more clearly determine the influencing factors of patient satisfaction, further research was necessary.

In the existing literature, the key influencing factors obtained by the research were different. Adhikari
Mukesh's research believed that socio-demographic characteristics were the key influencing factors, ${ }^{12}$ and age was the most critical influencing factor. Semegn Senait's research pointed out that communication skills with patients were the most critical influencing factor. ${ }^{9}$ Waqaar Diwan's study expressed that whether the patient has medical insurance and the length of consultation time were the key influencing factors. ${ }^{13}$ Fang Jinming's research more accurately pointed out three key influencing factors: "Medical staff's service attitude", "Medical staff services technology" and "Hospital convenience". 2 The conclusions of the existing literature were different and full of controversy.There is still a strong need for further research.

Through the literature review related to satisfaction in recent years, it could be seen that the related factors of Chinese's outpatient satisfaction were closely related to the quality and efficiency of medical services, the attitude of medical staff, and the treatment environment. The quality of medical services mainly refers to the accuracy and effectiveness of diagnosis. ${ }^{5}$ The efficiency of medical services included the convenience of making appointments for diagnosis and treatment and charging convenience. ${ }^{6,7}$ Attitudes of medical staff included the attitudes of doctors and nurses and the attitudes of other personnel, which were manifestations of doctor-patient relationships. ${ }^{8,14}$ In addition, treatment environmental factors included medical equipment, sanitation, comfort, and accuracy of guidelines. ${ }^{2}$ However, relevant literature in recent years showed that hospitals in different regions with different stages of development had their differences in the performance of outpatient satisfaction. In addition, most of the research samples at this stage were small, the number of hospitals studied was small, and the type of them was single. Regional differences, small samples and monotonous type of hospital made it difficult to generalize the conclusions of these studies in different regions and types of hospitals. This research on critical factors affecting the satisfaction of outpatients in different regions could enrich relevant researches, provide reference data that may be needed for related disciplines, and provide suggestions for government departments to promote the reform of the medical and health service system and formulate health policies. $^{2,4,15}$

Hence, this study aimed to understand the current level of patient satisfaction in 16 large public hospitals in the Zhejiang Province of China by constructing a statistical model through a large-scale field survey. 


\section{Materials and Methods}

\section{Sampling Design}

This study was conducted in 16 tertiary hospitals in the Zhejiang Province of China in 2018. The area has abundant medical resources and a large population, and there are a large number of tertiary hospitals with comprehensive range of types. Outpatients included permanent residents and foreign residents. Conclusions drawn from the survey were representative and could show the current status of patient satisfaction and its affecting factors in tertiary hospitals in developed areas of China.

Sample size calculation formula as follow, $n=\frac{u^{2} \alpha / 2 p(1-p)}{\delta^{2}}$. We used the calculation formula for the sample content of the Cross Sectional Study.In formula, $\mathrm{n}$ was the required minimum sample size; $\alpha$ was $0.05, u$ is the two-sided critical value of the normal distribution, $u_{\alpha / 2}=1.96 ; \mathrm{P}$ was the prior positive rate of the research, and it is estimated that the total number of patients in this survey is satisfied with positive The rate is $80 \%$, and the allowable error a is set to $1 \%$. The calculation process is as follows: $n=\frac{1.96^{2} * 0.8(1-0.8)}{0.01^{2}}=6146.56$

We conducted random sampling of outpatients in these 16 hospitals according to the distribution of the outpatient departments. According to the total amount of outpatient services in each hospital, the effective survey sample size of each hospital was set to be at least 240 and at most 600 people. The effective sample was 6,480 people. Investigators conducted face-to-face data collection by using surveys. Surveys were conducted once a month, 12 times throughout the year. Investigators held PAD terminal equipment to carry out inquiry surveys, uploaded of survey data in real-time to ensure the accuracy of the data.

\section{Questionnaire Design}

The questionnaire includes two parts. The first part is the characteristics of patients, including "gender", "age" (18-30, 31-45, 46-60,>60), "marriage", "profession" (Enterprise/company employers, Enterprise/company employees, Freelancers/small private businesses, Retired people, Others) "education", “ one year's household income(RMB)", "medical insurance type" (can be divided into Urban Employee Basic Medical Insurance (UEBMI), Residents Basic Medical Insurance (RBMI), New Rural Cooperative Medical Insurance (NRCMI), Free medical treatment, No social health insurance) "permanent resident", "registration category" (divided into general consultation and expert consultation), "outpatient department" (divided into internal medicine, surgery, gynecology, pediatrics, and Ophthalmology \& Otorhinolaryngology) "hospital type" (General hospital, specialist hospital, Chinese medicine hospital). Satisfaction score included four dimensions: service quality, service efficiency, service attitude, and hospital environment. The service quality dimension consisted of five factors: "Transparency in fees," "Reasonable inspection and laboratory tests," "Accurate diagnosis," "Treatment effect" and "Nursing level." Service efficiency included four factors: "Convenience of registration," "Convenience of appointment diagnosis and treatment," "Convenience of taking orders and medicines" and "Convenience of charging." The service attitude had five factors: "Doctor's attitude," " informed consent," " privacy protection," "Nurse's attitude" and "Other staff's attitude." The hospital environment included three factors: "Guidelines accuracy," "Service facilities," and "Environmental sanitation and comfort." In order to facilitate knowledge to the respondents and ensure accuracy. The satisfaction question used Likert's five-point method. Grant 100 points for very satisfied, 80 points for satisfied, 60 points for moderate, 40 points for dissatisfied and 20 points for very dissatisfied. ${ }^{9}$ The overall satisfaction of outpatients is the mean score from all criteria.For the second part of the questionnaire, Kaiser-Meyer-Olkin test and Bartlett sphericity test were used to determine the representativeness and connection of those factors and the validity of the questionnaire structure. In addition, the Cronbach's $\alpha$ coefficient has been used to secure the consistency of the questionnaire.

\section{Inclusion and Exclusion Criteria}

The inclusion criteria were patients who are over 18 years old and willing to be investigated and have experienced all medical procedures. The exclusion criteria were an emergency and physical examination patients.

\section{Statistical Analyses}

Data was inputted by Excel 2010 and analyzed by SPSS19. The first step was to calculate the overall outpatient satisfaction of all dimensions, and the mean scores of satisfaction criteria in the second part of the questionnaire, then to carry out a descriptive analysis of patient characteristics, including the number of samples and composition ratio. The second step was to apply a univariate analysis of outpatient satisfaction (including independent 
sample $T$-test and ANOVA test) to determine the factors that affected outpatient scores under different patient characteristics. The third step was to perform binary logistic regression analysis on the descriptive data. In the above analysis, the confidence interval was set to $95 \%$. The overall satisfaction of outpatients and the satisfaction of different dimensions were set as dependent variables. Scores less than 80 (that is moderate, dissatisfied, very dissatisfied) are coded as " 0 " to represent dissatisfaction. A score equal to or above 80 (that is satisfied, very satisfied) are coded as "1" to represent satisfaction.

\section{Quality Control}

In terms of on-site investigation quality control, at first uniform training was conducted for investigators before the investigation officially started.Only the qualified ones were allow to perform their tasks. Secondly, PAD mobile terminals with CATI (Computer-Assisted Telephone Inquiry) access were applied, which facilitated not only the real-time adjustment of the quotas of a different hospital during the survey process but also remote supervision of the supervisors and the realtime data transmission. The synchronized recording of the respondents ensured the authenticity and validity of the collected data. Thirdly, in the specific survey process, all interviews were conducted independently and anonymously, and the personal privacy of interviewees was not involved in the survey, to collect the real thoughts of patients to the most extent. Finally, a supervisory system had been implemented. Supervisors needed to submit on-site investigation feedback of various hospitals, which recorded and explained the special circumstances of the hospital (such as abnormal patient flow, new service items, hospital construction, medical disputes). Data verifiers checked survey data and recording materials and repeated data analysis and proofreading to ensure the accuracy and reliability of the data used.

\section{Results}

\section{Questionnaire Test}

The Cronbach's $\alpha$ coefficient was 0.919 , which indicates that the questionnaire had a good internal consistency. The Kaiser-Meyer-Olkin was 0.947 , and the $\chi^{2}$ value of Bartlett's test of sphericity was 27,701.535 $(p<0.001)$, which indicated the factorability of the data in this survey was appropriate and adequate for factor analysis.

\section{Outpatient Satisfaction Score Status}

It can be known from Table 1 that the overall outpatient satisfaction score is $(87.13 \pm 9.12)$. The highest scored dimensional satisfaction is service efficiency satisfaction $(88.01 \pm 10.90)$, and the lowest score is the hospital environment $(86.22 \pm 11.03)$. The factor with the highest score on the service quality dimension is the level of care $(90.08$ \pm 12.15 ), and the factor with the lowest score is the treatment effect $(84.18 \pm 13.57)$.The factor with the highest score on the service efficiency dimension is the convenience of registration $(89.13 \pm 13.90)$, and the factor with the lowest score is the convenience of taking orders and medicines $(85.81 \pm 14.81)$.The factor with the highest score in the service attitude dimension is the doctor's attitude $(88.68 \pm 13.61)$, and the lowest score is other staff's attitude $(85.36 \pm 13.84)$. The highest-scored factor in the hospital environment dimension is guidelines accuracy (87.71 \pm 13.47 ), and the lowest-scored factor is environmental sanitation and comfort $(85.23 \pm 13.36)$.

\section{Statistical Description}

The number of samples in this survey is 6,840 . According to description analysis (Table 2). The majority of outpatients surveyed are women ( $\mathrm{N}=3780,59.7 \%)$. The age distribution is concentrated in $18-30(\mathrm{~N}=2980$, $46.1 \%)$ and $31-45$ years old $(\mathrm{N}=2593,40.0 \%)$, The sum of the two proportions exceeds $85 \%$ of the surveyed outpatients. Most of them are unmarried $(\mathrm{N}=4832$, $74.6 \%)$, enterprise/company employees $(\mathrm{N}=2357$, $36.4 \%$ ). Most of them are undergraduate/junior college $(\mathrm{N}=3876,59.8 \%$.). One year's household income (RMB) is mainly distributed between $60,000-100,000(\mathrm{~N}=1957$, $30.2 \%)$ and $110,000-150,000(\mathrm{~N}=2042,31.5 \%)$. The most common type of medical insurance is the Urban Employee Basic Medical Insurance ( $\mathrm{N}=3299$, 50.9\%). Most of the respondents are permanent residents $(\mathrm{N}=3299,86.7 \%)$. Most of the registration options are general outpatients $(\mathrm{N}=3679,56.8 \%)$. The internal medicine departments has the largest proportion of outpatients $(\mathrm{N}=2255,34.8 \%)$. Most of the surveyed outpatients came from general hospitals $(\mathrm{N}=3600,55.6 \%)$.

\section{Univariate Analysis}

Take overall outpatient satisfaction as the dependent variable, and patient characteristics as the independent variable and grouping factor. Independent-sample $T$-test was performed on two-factor grouping variables, and 
Table I Overall and Dimensions Outpatient Satisfaction Score

\begin{tabular}{|c|c|c|c|c|}
\hline & Criteria & Factors & Dimension & Overall \\
\hline \multirow[t]{5}{*}{ Service quality } & \multirow[t]{5}{*}{5} & Transparency in fees & $87.19 \pm 13.52$ & \multirow[t]{5}{*}{$86.90 \pm 10.09$} \\
\hline & & Reasonable inspection and laboratory tests & $87.88 \pm 12.94$ & \\
\hline & & Accurate diagnosis & $86.15 \pm 13.59$ & \\
\hline & & Treatment effect & $84.18 \pm 13.57$ & \\
\hline & & Nursing level & $90.08 \pm 12.15$ & \\
\hline \multirow{4}{*}{$\begin{array}{l}\text { Service } \\
\text { efficiency }\end{array}$} & \multirow[t]{4}{*}{4} & Convenience of taking orders and medicines & $85.8 I \pm|4.8|$ & \multirow[t]{4}{*}{$88.01 \pm 10.90$} \\
\hline & & Convenience of appointment diagnosis and treatment & $88.76 \pm 15.42$ & \\
\hline & & Convenience of registration & $89.13 \pm 13.90$ & \\
\hline & & Convenience of charging & $88.53 \pm 13.10$ & \\
\hline \multirow[t]{5}{*}{ Service attitude } & \multirow[t]{5}{*}{5} & Doctor's attitude & $88.68 \pm|3.6|$ & \multirow[t]{5}{*}{$87.20 \pm 10.50$} \\
\hline & & Informed consent & $86.69 \pm 14.40$ & \\
\hline & & Privacy protection & $88.62 \pm 13.60$ & \\
\hline & & Nurse's attitude & $86.89 \pm 14.59$ & \\
\hline & & Other staff's attitude & $85.36 \pm 13.84$ & \\
\hline \multirow{3}{*}{$\begin{array}{l}\text { Hospital } \\
\text { environment }\end{array}$} & \multirow[t]{3}{*}{3} & Guidelines accuracy & $87.7 \mid \pm 13.47$ & \multirow[t]{3}{*}{$86.22 \pm 11.03$} \\
\hline & & Service facilities & $85.72 \pm 14.67$ & \\
\hline & & Environmental sanitation and comfort & $85.23 \pm 13.36$ & \\
\hline $\begin{array}{l}\text { Overall } \\
\text { satisfaction }\end{array}$ & & & & $87.13 \pm 9.12$ \\
\hline
\end{tabular}

ANOVA test was showed on grouping variables with more than two factors. Table 3 obtained. According to Table 3, there was no statistically significant difference in "Marriage" "One year's household income (RMB)", "Permanent residents" and "Hospital type" ( $p>0.05)$, the other factors exhibited significant differences $(p<0.05)$. On the gender factor, male scored the strongest $(87.50$ $\pm 8.92)$ and female scored the weakest $(86.88 \pm 9.24)$. On professional factors, civil servant/institutional personnel scored the highest $(87.68 \pm 8.93)$ and enterprise/company employers scored the lowest (86.32 \pm 9.00$)$. Regarding education, the undergraduate/junior college score (87.48 \pm 9.19$)$ was the highest, and the postgraduate had the lowest score $(86.13 \pm 9.15)$. In terms of the type of medical insurance, the score of free medical treatment care was the highest $(88.46 \pm 8.34)$, and the score of no social medical insurance was the lowest $(86.67 \pm 9.47)$.
As well as the outpatient type factor, the expert consultation score $(87.32 \pm 8.96)$ was higher than that of the general outpatient (86.98 \pm 9.24$)$. Specifically, the overall outpatient satisfaction of male, civil servant/institutional personnel, undergraduate/junior college, free medical treatment and expert consultation was significantly stronger than that of other groups.

\section{Multivariate Analysis}

Logistic regression analysis was used to analyze the patient characteristics and outpatient satisfaction. The multivariate analysis method used was binary logistic regression analysis (Table 4). According to Table 4, the three factors of "marriage", "One year's household income (RMB)" and "Registered category" have no statistically significant differences in overall outpatient satisfaction or dimensional outpatient satisfaction ( $p>0.05$ ). 
Table 2 Patient Characteristics of Outpatients

\begin{tabular}{|c|c|}
\hline Patient Characteristics & $\mathbf{N}(\%)$ \\
\hline \multicolumn{2}{|l|}{ Gender } \\
\hline Male & $2610(40.3 \%)$ \\
\hline Female & $3780(59.7 \%)$ \\
\hline \multicolumn{2}{|l|}{ Age } \\
\hline $18-30$ & $2980(46.1 \%)$ \\
\hline $31-45$ & $2593(40.0 \%)$ \\
\hline $46-60$ & $578(8.9 \%)$ \\
\hline$>60$ & $319(4.9 \%)$ \\
\hline \multicolumn{2}{|l|}{ Marriage } \\
\hline Unmarried & $1648(25.4 \%)$ \\
\hline Married & $4832(74.6 \%)$ \\
\hline \multicolumn{2}{|l|}{ Profession } \\
\hline Civil servant/institutional personnel & $990(15.3 \%)$ \\
\hline Enterprise/company employers & $315(4.9 \%)$ \\
\hline Enterprise/company employees & $2357(36.4 \%)$ \\
\hline Freelancers/small private businesses & I 554 (24.0\%) \\
\hline Retired people & $415(6.4 \%)$ \\
\hline Others & $849(13.1 \%)$ \\
\hline \multicolumn{2}{|l|}{ Education } \\
\hline Junior high school and below & $1000(15.4 \%)$ \\
\hline Senior high school/technical secondary school & 1327 (20.5\%) \\
\hline Undergraduate/junior college & $3876(59.8 \%)$ \\
\hline Postgraduate & $277(4.3 \%)$ \\
\hline \multicolumn{2}{|l|}{ One year's household income (RMB) } \\
\hline$\leq 50,000$ & $275(4.2 \%)$ \\
\hline $60,000-100,000$ & 1957 (30.2\%) \\
\hline $110,000-150,000$ & $2042(31.5 \%)$ \\
\hline $160,000-200,000$ & $1100(17.0 \%)$ \\
\hline $210,000-250,000$ & $505(7.8 \%)$ \\
\hline $260,000-300,000$ & $258(4.0 \%)$ \\
\hline$>300,000$ & $343(5.3 \%)$ \\
\hline \multicolumn{2}{|l|}{ Medical insurance type } \\
\hline Urban Employee Basic Medical Insurance & 3299 (50.9\%) \\
\hline Urban residents' medical insurance & $1049(16.2 \%)$ \\
\hline New Rural Cooperative Medical Insurance & $797(12.3 \%)$ \\
\hline Free medical treatment & $164(2.5 \%)$ \\
\hline No social health insurance & $1171(18.1 \%)$ \\
\hline \multicolumn{2}{|l|}{ Permanent residents } \\
\hline Yes & $5620(86.7 \%)$ \\
\hline No & $860(13.3 \%)$ \\
\hline \multicolumn{2}{|l|}{ Registered category } \\
\hline General outpatient & $3679(56.8 \%)$ \\
\hline Expert consultation & $280 I(43.2 \%)$ \\
\hline
\end{tabular}

(Continued)
Table 2 (Continued).

\begin{tabular}{|l|l|}
\hline Patient Characteristics & N (\%) \\
\hline Outpatient department & \\
Internal medicine department & $2255(34.8 \%)$ \\
Surgical department & $1800(27.8 \%)$ \\
Obstetrics and gynecology department & $980(15.1 \%)$ \\
Pediatrics department & $362(5.6 \%)$ \\
Ophthalmology \& Otorhinolaryngology & $1083(16.7 \%)$ \\
\hline Hospital type & \\
General hospital & $3600(55.6 \%)$ \\
Chinese medicine hospital & $1320(20.4 \%)$ \\
Specialist hospital & $1560(24.1 \%)$ \\
\hline
\end{tabular}

\section{Overall Outpatient Satisfaction}

There were six factors having statistically different in overall outpatient satisfaction. In terms of gender factors, female's satisfaction $(p<0.001, O R=0.789)$ was significantly lower than that of male. In terms of professional factors, the satisfaction of enterprise/company employers $(\mathrm{P}<0.001, \mathrm{OR}=0.595)$ was significantly lower than all other factors in the same group. The satisfaction degree of postgraduate $(\mathrm{p}=0.022, \mathrm{OR}=0.668)$ in terms of educational factors was significantly lower than other factors in the same group. Among the factors of medical insurance type, satisfaction with free medical treatment was the highest $(p=0.016, O R=1.859$ ), while satisfaction with no social health insurance $(\mathrm{p}=0.008, \mathrm{OR}=0.002)$ was the lowest. The satisfaction of the floating population $(\mathrm{p}=0.022$, $\mathrm{OR}=1.259$ ) was significantly higher than that of permanent residents. Paediatrics $(\mathrm{p}=0.032, \mathrm{OR}=0.748)$ had the lowest satisfaction among the outpatient factors. The degree of satisfaction of Chinese Medicine Hospital ( $\mathrm{p}=0.016$, $\mathrm{OR}=0.825$ ) in the hospital type factor was the lowest.

\section{Service Quality}

There were only two factors statistically different in the dimension of service quality: gender and medical insurance type. There was no statistical difference in other factors $(p>0.05)$. On the gender factor, females $(p=0.033$, $\mathrm{OR}=0.854$ ) had significantly lower satisfaction levels than male. The satisfaction of new rural cooperative medical insurance $(p=0.011, O R=0.742)$ and no social health 


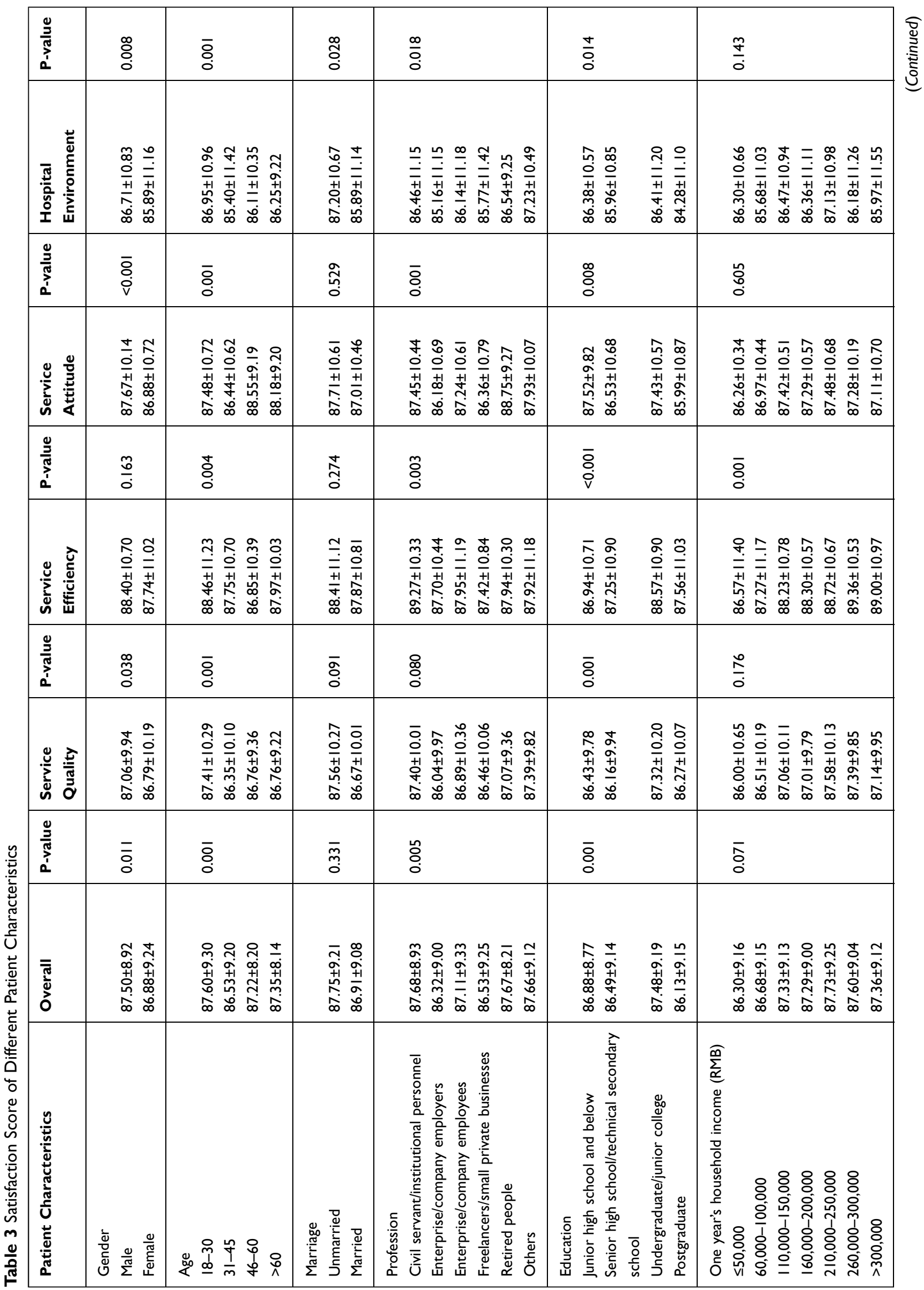




\begin{tabular}{|c|c|c|c|c|c|c|c|}
\hline בְ & 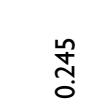 & & & $\frac{\sigma}{0}$ & ợ & $\bar{\circ}$ & $\bar{\circ}$ \\
\hline 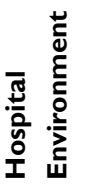 & 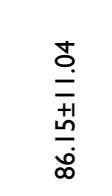 & 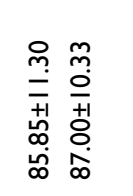 & 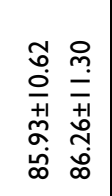 & 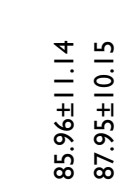 & 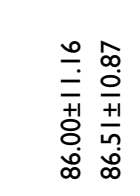 & 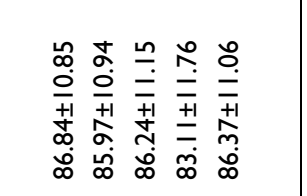 & 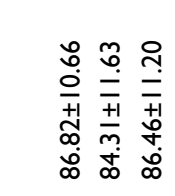 \\
\hline בְ & б్ & & & ஜ̊̊ & 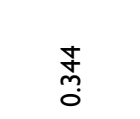 & $\bar{o}$ & $\begin{array}{l}\tilde{o} \\
\stackrel{0}{0}\end{array}$ \\
\hline 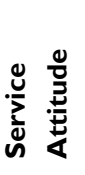 & 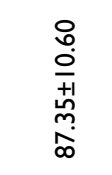 & 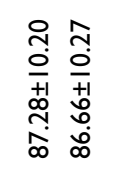 & 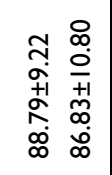 & 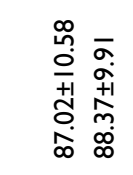 & 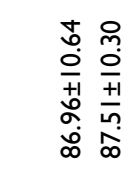 & 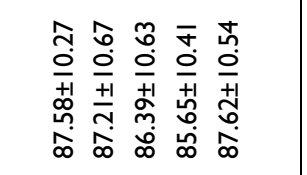 & 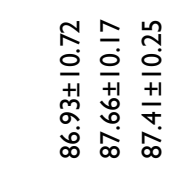 \\
\hline בֶ & $\bar{\circ}$ & & & ¿̊̊ & 弚 & চ্口 & ڤ̊̊̆ \\
\hline . & 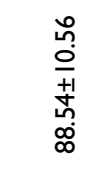 & $\begin{array}{ll}\infty & \hat{\infty} \\
\infty & \infty \\
0 & 0 \\
+1 & +1 \\
0 & 0 \\
0 & 0 \\
\infty & \infty\end{array}$ & 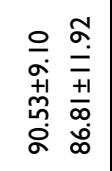 & 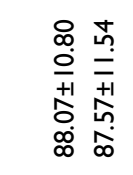 & 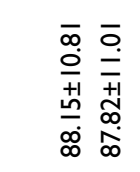 & 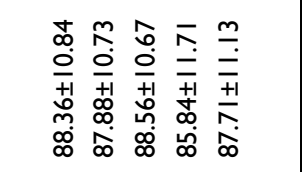 & 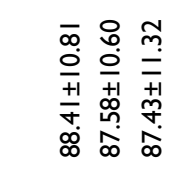 \\
\hline בֶ. & ôे & & & $\frac{m}{o}$ & $\begin{array}{l}\text { 巳े } \\
0\end{array}$ & $\begin{array}{l}\text { ồ } \\
\text { Oें }\end{array}$ & \begin{tabular}{l}
\multirow{\Delta}{0}{} \\
$\stackrel{0}{0}$
\end{tabular} \\
\hline 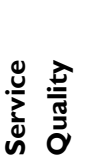 & $\begin{array}{l}\frac{\infty}{0} \\
\frac{0}{ \pm} \\
\frac{1}{+} \\
\infty\end{array}$ & $\begin{array}{ll}\text { co } & \infty \\
\sigma & \infty \\
+1 & +1 \\
0 & +1 \\
0 & 0 \\
\infty & \infty\end{array}$ & 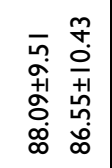 & 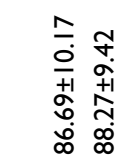 & 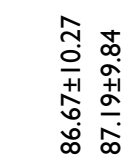 & 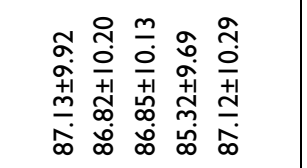 & 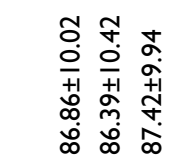 \\
\hline בֶ & $\begin{array}{l}\text { ơ } \\
\text { o }\end{array}$ & & & $\frac{\infty}{\pi}$ & $\begin{array}{l}\text { ڤे } \\
0 \\
0\end{array}$ & $\bar{o}$ & $\frac{\sigma}{0}$ \\
\hline 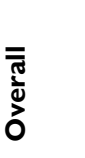 & 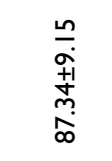 & 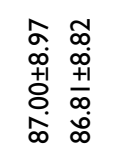 & 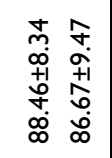 & 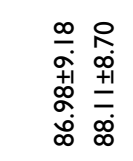 & 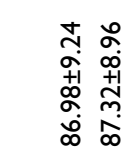 & 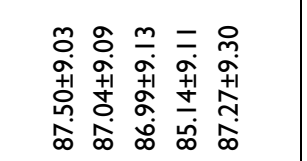 & 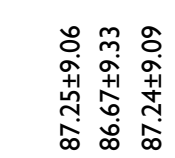 \\
\hline 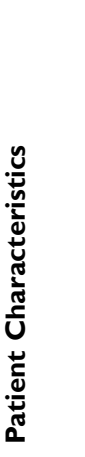 & 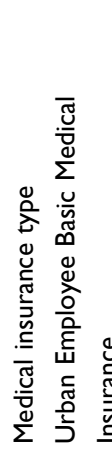 & 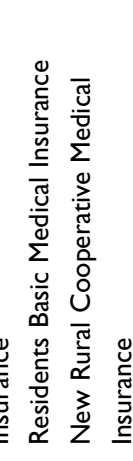 & 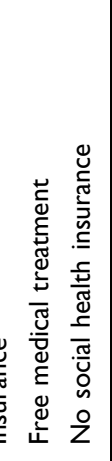 & 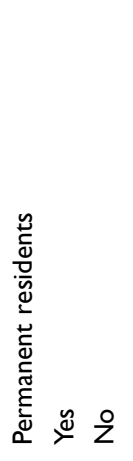 & 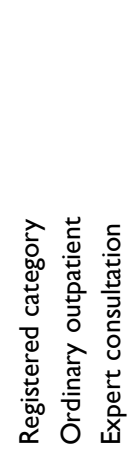 & 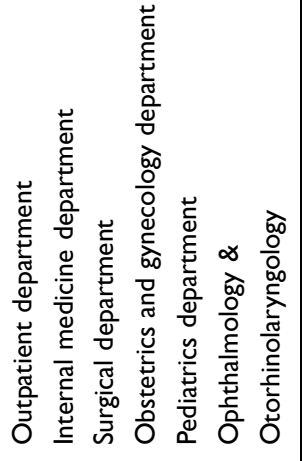 & 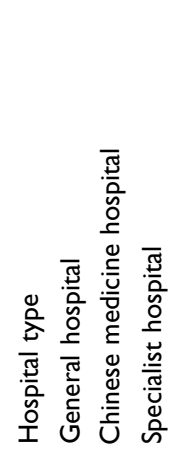 \\
\hline
\end{tabular}




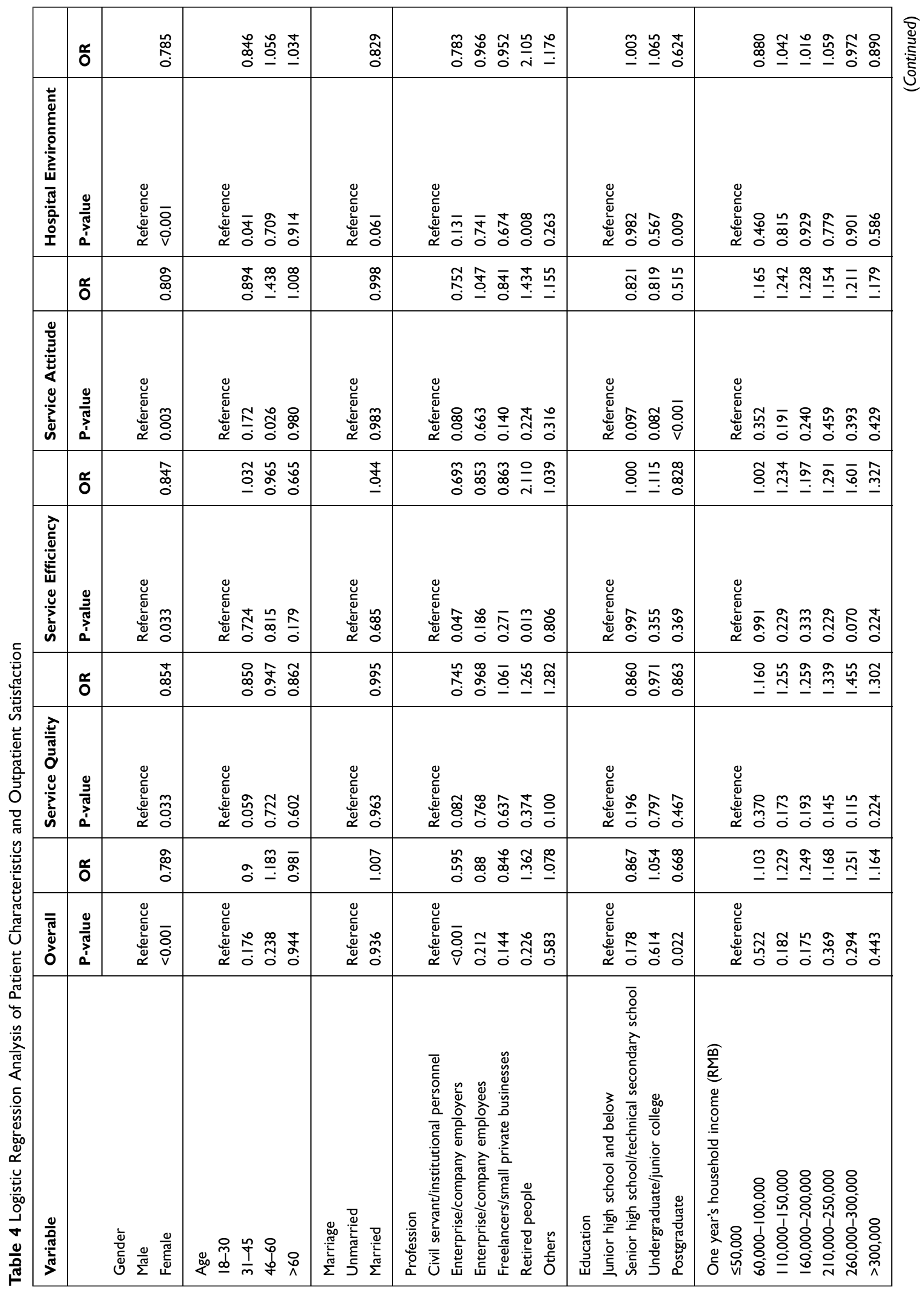




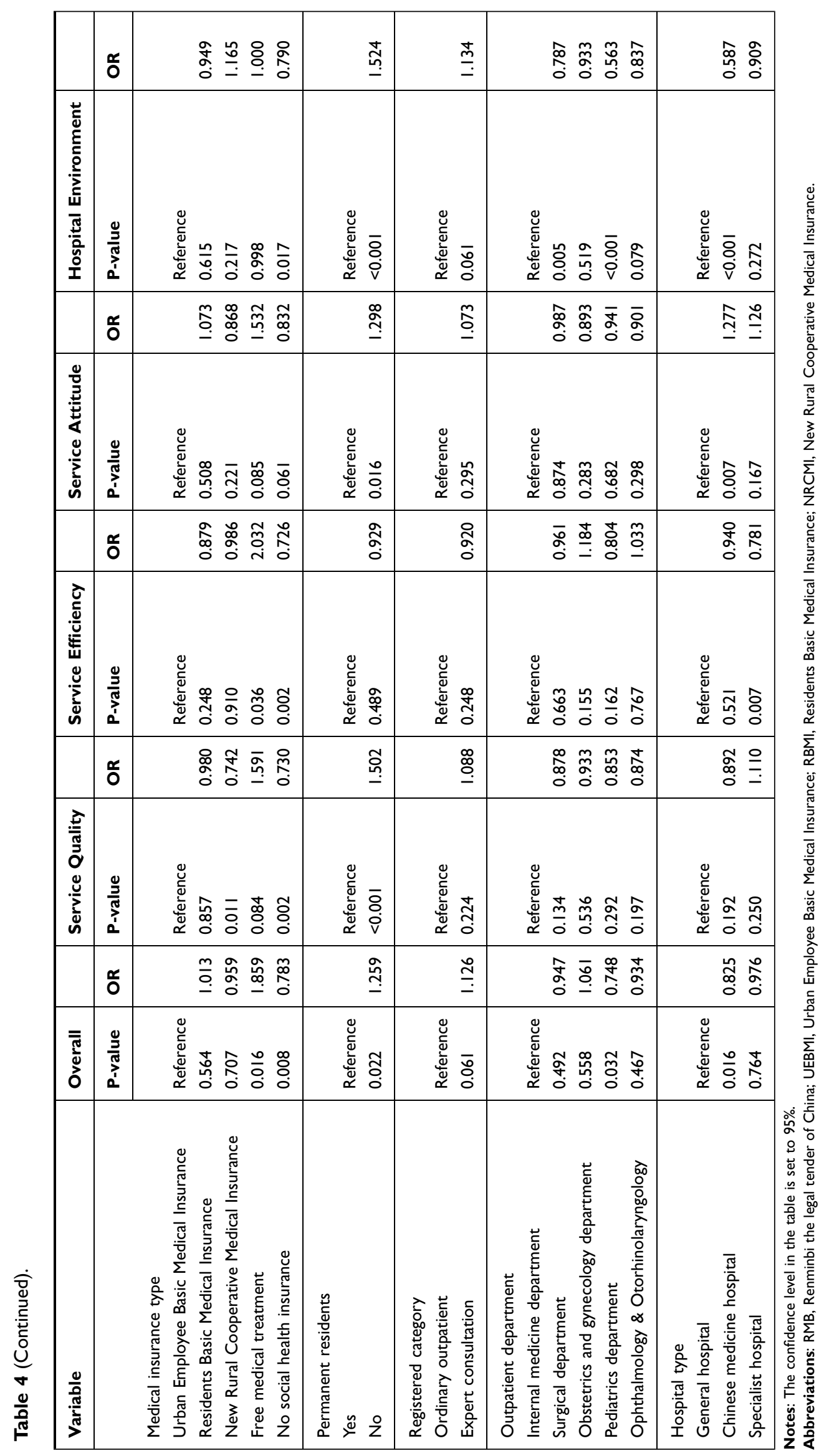


insurance $(\mathrm{p}=0.002, \mathrm{OR}=0.730)$ were significantly lower than other factors in the same group when referring to the medical insurance types.

\section{Service Efficiency}

Four factors had significant statistical differences in the dimension of service efficiency. In terms of gender, females $(p=0.033, O R=0.947)$ had significantly lower satisfaction levels than male. Enterprise/company employers' satisfaction level ( $p=0.047, O R=0.693$ ) was significantly lower than other factors in the same group, while the satisfaction level of retired people $(p=0.013$, $\mathrm{OR}=2.110$ ) was at the same level, and the highest bit of the group factor. Among the medical insurance types, free medical treatment $(p=0.036, O R=2.032)$ had the highest satisfaction, and the satisfaction level of no social health insurance was the lowest $(\mathrm{p}=0.002, \mathrm{OR}=0.726)$. Among the hospital types, the satisfaction of specialist hospitals ( $p=0.007, O R=0.781$ ) was significantly lower than that of other hospital types.

\section{Service Attitude}

There are significant statistical differences in five factors in the service attitude dimension. Among the gender factors, the satisfaction of female $(p=0.003, O R=0.809)$ was significantly lower than that of male. Regarding age, the satisfaction level of 36-60 years old was significantly higher than other factors in the same group. The satisfaction of postgraduate $(\mathrm{p}<0.001, \mathrm{OR}=0.515)$ in term of the educational factors was the lowest among the same group of factors. The satisfaction of floating population $(p=0.016, O R=1.298)$ was significantly higher than that of permanent residents. Traditional Chinese Medicine Hospital ( $\mathrm{p}=0.007, \mathrm{OR}=1.277$ ) had the highest satisfaction level among hospital type factors.

\section{Hospital Environment}

There were eight factors in the hospital environment dimension having statistically significant differences. In terms of gender, female $(\mathrm{p}<0.001, \mathrm{OR}=0.785)$ were less satisfied than male. Among the age factors, 31-45 years old ( $\mathrm{p}=0.041, \mathrm{OR}=0.846)$ satisfaction was significantly lower than other factors in the same group. Retired people $(p=0.008, O R=2.105)$ had the highest satisfaction among the profession. Among the factors of education, postgraduate $(p=0.017, O R=0.790)$ had the lowest satisfaction. The satisfaction level of the floating population $(p<0.001$, $\mathrm{OR}=1.524$ ) was significantly higher than that of permanent residents. The satisfaction degree of the surgery department $(\mathrm{p}=0.005, \mathrm{OR}=0.787)$ and paediatrics department $(\mathrm{p}<0.001, \mathrm{OR}=0.563)$ in the treatment department was significantly lower than other factors, and the satisfaction of paediatrics department was the lowest. Among the factors of hospital type, the satisfaction degree of Chinese traditional medicine hospital $(\mathrm{p}<0.001$, $\mathrm{OR}=0.587$ ) was the lowest.

\section{Discussion}

Outpatient satisfaction was a concept derived from customer satisfaction theory. This concept could reflect the overall strength of the hospital and help provide a reference for the hospital to improve its medical services. ${ }^{16}$ Through a 12-month survey of 16 public tertiary hospitals in Zhejiang Province, we had established the key influencing factors that affect the satisfaction of outpatients.

\section{The Service Efficiency Dimension Had the Highest Score, While the Hospital Environment Dimension was the Opposite}

In terms of overall satisfaction, the final procedure for satisfaction scoring performed well, and the main shortcomings were in the dimensions of service quality and hospital environment. The best performance was in the service efficiency dimension.

From the satisfaction score results, it showed that accurate diagnosis and treatment effect in the service quality dimension had low satisfaction. This result was also unexpected. Previous studies had shown that patients were more dissatisfied with medical expenses in this dimension. $^{2-4,17}$ This lower satisfaction could be explained by the patients' high expectations for the medical services of tertiary hospitals and the gap between ideal and reality. Thomas's research indicated that patient experience may not directly relate to the quality of medicinal care, but patient satisfaction is closely related to high-quality treatment procedures. ${ }^{18}$ Tertiary hospitals were institutions that could provide the best medical services in China's public healthcare system. Therefore, it could be inferred that the gap between high expectations and actual medical services would affect satisfaction. Regarding this-Juliana de Lima Lope's research made it clear that the outpatient satisfaction of nurses depended on the expectations of patients. ${ }^{19}$ In the results, the highest degree of satisfaction with 
service quality was the nursing level, indicating that the nurses' care met the expectations of patients. Similarly, it could be inferred that many patients in tertiary hospitals could not meet their expectations when receiving medical services.

The satisfaction score on the service efficiency dimension was the highest among the four dimensions. It could be seen that China's tertiary hospitals had an outstanding performance in service efficiency. In this dimension, the only convenience of taking orders and the medicines score was relatively low. This could be supported by the research of Wenya Yu and Jinming Fang. That was, the waiting time for the process of receiving treatment, nursing, and medicine collection in tertiary hospitals in China was long due to a large number of patients. ${ }^{2,3}$ In response to this situation, China had implemented a hierarchical diagnosis and treatment system and a two-way referral system, but such reform measures had not changed the high demand of patients for tertiary hospitals, because the patients' demand for high-quality medical services could not be met by community hospitals. It was more important to improve the treatment level of the medical institutions other than tertiary hospitals. Besides, the process should be optimized to reduce patient waiting time and improve treatment efficiency.

The satisfaction survey results of the service attitude dimension showed that tertiary hospitals still had many shortcomings in this respect. Patients' satisfaction with informed consent was low. Existing research suggested that improving information transparency and accessibility could effectively improve patient satisfaction and treatment effects. ${ }^{20}$ The attitudes of staff other than doctors were not good in terms of satisfaction. Studies showed that the satisfaction of doctors was lower than that of nurses in the past. ${ }^{3}$ The results of this survey were contrary to these conclusions, indicated that the doctor-patient relationship reform implemented in the third-level hospitals in Zhejiang Province were effective. However, the hospital had neglected service attitude training for personnel other than doctors. Min Li's research explained that medical staff in developed areas offered high standard diagnosis and treatment but ignored to empathize with patients, which was consistent with the results of this research. ${ }^{21}$ Robert Szyca's research showed that the empathy of hospital staff and patient expectations were as important as material welfare. ${ }^{15}$ Another study showed that the courtesy of the medical staff and administrative staff was closely related to high patient satisfaction level. ${ }^{22}$ In short, respecting patients and their rights is an important measure to improve outpatient satisfaction. The coverage of this initiative should not be limited to doctors.

The hospital environment dimension was the one with the lowest score among all the dimensions. The results showed that the accuracy of the guidelines in tertiary hospitals was high.

Nevertheless, the standard was low in terms of service equipment, environmental comfort and hygiene. Linlin Hu's research on environmental factors in outpatient satisfaction had also reached the same conclusions. ${ }^{14}$ On the surface, this reflected the insufficient construction of the outpatient environment of hospitals in developed areas in China. However, existing research suggested that as top medical institutions in China, tertiary hospitals not only had a lot of excellent equipment but also made full use of advanced equipment. ${ }^{23}$ The reason for this situation might lie in the contradiction between the large demand of Chinese patients for tertiary hospitals and the high expectations of patients. Because of the great demand from patients, the supply of hospitals was always tight. Therefore, the environmental sanitation and comfort of the hospital cannot be maintained due to a large number of patients and noise. In particular, there were more outpatients than inpatients. In this situation, improving the environment or equipment did not make much sense for improving outpatient satisfaction. The service capabilities of primary and intermediate medical institutions should be strengthened, in order to divert patients from tertiary hospitals and change the situation in which the demand of tertiary hospitals exceeded their capacity. Of course, improving the hospital environment was also an important measure to improve hospital satisfaction. Zachary Sanford mentioned in his research that the aesthetic experience of outpatient clinics might have a positive effect on improving satisfaction with the hospital environment. ${ }^{24}$

\section{Socio-Demographic Characteristics That Have Influence on Satisfaction}

Improving outpatient satisfaction had always been an important goal of China's medical and health system reform. At present, most of the relevant researches in China were inadequate for patient factors. The research samples were small, and the type of hospital was relatively monotonous. ${ }^{1,3,10,25}$ Based on these deficiencies. This study had improved the survey content and used statistical description, single-factor analysis, and multi-factor analysis to determine the factors that had a greater impact on satisfaction in patient characteristics. In this regard, 
optimization suggestions were made to improve the satisfaction of outpatients and promote the reform of the medical and health system. Results show that gender, profession, education, medical insurance, permanent residents outpatient department and hospital type are significant influencing factors.

Gender, as the most basic demographic feature, had been studied in the current research field. From the results, it could be seen that male satisfaction is significantly higher than females in terms of overall and every dimensionality. However, it could be understood from the available research that there were many differences when gender taking as an influencing factor in different surveys. There were both women with higher satisfaction ${ }^{5,26}$ and men with higher satisfaction. ${ }^{3,27,28}$ There were also studies that showed that gender was not a factor affecting the satisfaction. ${ }^{29}$ The results of this study could be explained as: women are more sensitive to medical expenses than men and may have higher expectations of medical services' quality. ${ }^{30}$

In the professional group, the overall satisfaction of civil servants and retirees was significantly higher than other professions. Robert Szyca's research showed that this result was consistent with worldwide trends. ${ }^{19}$ The satisfaction of corporate management was the lowest. This result was not difficult to understand. Civil servants and retirees had more disposable time. They lived gentle and stable lives. They had low expectations for outpatient clinics and were easier to satisfy. However, corporate management often had limited time, heavy workloads, towering income, and high expectations for medical services quality. The results showed that the satisfaction of corporate management for service quality and hospital environment was relatively low. At present, studies had proposed to pay more attention to the medical history and current situation of patients to offset the impact of the profession on satisfaction. ${ }^{9}$ This meant that hospitals should pay attention to the patients' professions in medical records, and reduce unnecessary medical tangles caused by the dissatisfaction of medical services.

The surprising phenomenon of the education was that previous studies had shown the outpatient satisfaction level and education level is inversely proportional. ${ }^{5,30}$ This was because the higher of patients' education level the higher their expectations for medical services. In this survey, the degree of satisfaction of postgraduate was lower, but the satisfaction of undergraduate/junior college was higher. However, there were also studies that showed that patients with higher education levels could understand the hospital's operating rules and treatment procedures, ${ }^{4,14,16}$ as well as health-related policies better than those with lower education levels, therefore, they tended to have higher satisfaction. The results in the service efficiency dimension had supported this statement, the satisfaction of undergraduates and graduate students was significantly lower in this dimension. In short, the higher understanding and cognitive ability of the higher educated people made them more satisfied in some aspects, but it also gave them higher expectations and requirements for the quality of outpatient services comparing to the loweducated people.

The overall satisfaction of public medical insurance in the medical insurance criteria was significantly higher than that of other types of medical insurance. It was easy to understand that the medical services and reimbursement offering by public medical insurance were the best among them. From the results, it could be understood that the higher the reimbursement limit and benefit level of the medical insurance, the higher the overall satisfaction. Urban Employee Basic Medical Insurance (UEBMI) had a higher reimbursement ratio than Residents Basic Medical Insurance (RBMI), and its satisfaction was also higher than the latter. Similarly, patients who received UEBMI were more satisfied than those who received New Rural Cooperative Medical Insurance (NRCMI). Past research ${ }^{28,30}$ also introduced similar results to support this conclusion. Therefore, government departments needed to further adjust health and health policies to balance the fairness of different types of medical insurance. Jay Pan's research illustrated China's recent efforts in multi-medical insurance and universal coverage. ${ }^{23}$ But this survey results showed that there were a large number of patients who did not receive medical insurance $(\mathrm{N}=1171,18.1 \%)$. Those patients had the lowest overall satisfaction in this dimension. Studies had pointed out that China's medical insurance had poor resistance to catastrophic expenditures. ${ }^{31}$ Therefore, it needed to pay more attention to promote the awareness of medical insurance to the society. Zhihua Yan and Dongxiao Gu's studies figured out since the implementation of NRCMI, it had played a very positive role in improving the satisfaction of rural, low-income and elderly patients. ${ }^{33,34}$ The conclusions of LinLin Hu's research emphasized the importance of designing better public welfare insurance. ${ }^{31}$

The satisfaction of the floating population is higher than that of permanent residents. The majority of 
permanent residents were from Zhejiang province, and the floating population was usually from rural areas. This result was consistent with most of the previous surveys. ${ }^{29}$ Floating population often had lower expectations for medical treatment in developed areas, while local residents had higher living standards and expectations for the quality of medical services. Thus the satisfaction of permanent residents was significantly higher than that of the floating population in the other dimensions besides service efficiency. The study of Enkhjargal Batbaatar and Yan proved that this phenomenon existed both in China and internationally. ${ }^{33,35}$ On the other hand, there was no statistically significant difference in the overall satisfaction scores in the single-factor analysis, which could also indicate, to a certain extent, that the overall difference in medical services received by residents and the floating population was relatively small. Permanent residents demanded more medical details and were more sensitive.

The satisfaction of surgery and paediatrics in all outpatient departments was significantly low. One reason for the low paediatric satisfaction was extreme shortage of pediatric medical staff in China. Li Ji's research showed that Chinese pediatric practitioners had low professional satisfaction and high burnout. ${ }^{36}$ Shanshan Xu's research proved the high turnover rate of Chinese pediatric nurses. ${ }^{37}$ The second was that the respondents of the pediatric satisfaction questionnaire were usually the guardian of the patients, both of them would directly affect the accuracy of result. For Chinese hospitals, in most cases, outpatient surgery would be affected by limited medical resources, environmental noise caused by patients' symptoms, and hygiene problems caused by excessive staff. In addition, Adugnaw Berhane's research had shown that more outpatients who go to surgery have a negative perception of their health status, and their satisfaction tends to be at a low level. ${ }^{38}$

In single factor analysis, three types of hospitals had no statistically significant differences in overall satisfaction. Specialist hospitals were more targeted and performed best in terms of service. The outpatient services of the Chinese Medical Hospital performed better in terms of service attitude. Studies had shown that when patients choosing a Chinese medical hospital, they would pay attention to doctors who were well-known for their great medical skills. The level of the hospital had little effect on them. The judgment of patients on doctors determined their satisfaction with doctors. ${ }^{1}$ This could also explain the highest score in the satisfaction of outpatients was attained by the traditional Chinese hospitals. It could be explained that the demand for outpatient services in general hospitals is greater than the other two, and it needed to deal with a large number of patients efficiently. Doctors had to allocate shorter service time for each patient. Zachary Sanford's research showed that waiting time was an important factor in patients' perception of the quality of medical services. ${ }^{24}$ This means general hospitals perform better in terms of service efficiency. However, the existing literature was not enough to explain the results, so further research was needed to explore the reasons behind the results.

\section{Main Findings}

Through our research, we found that the key influencing factors of outpatient satisfaction in public tertiary hospitals in Zhejiang Province are more reflected in the subjective feelings of outpatients. In the results, many factors in the quality and efficiency dimensions of medical services can be objectively reflected in the final treatment results, and the overall scores of these two dimensions are not low. The two service facilities and environmental sanitation and comfort with the lowest scores in the hospital environment dimension with the lowest score in the results are subjective feelings, and it needs to be emphasized that the public tertiary hospital is already the highest-level hospital in China. The equipment and environment are the best in the hospital. Existing studies also show that patients subjectively have expectations of high-level hospitals when choosing a hospital and that patients have a good service experience process that will satisfy them more than the results. ${ }^{39}$ While high-level hospitals are generally better than lower-level hospitals in terms of service quality, more attention should be paid to patients' medical experience at the level of tertiary hospitals. And combined with the scores of different social demographic characteristics, it can be seen that women, civil servant/institutional personnel, Postgraduate, Registered category etc. have higher expectations of medical service experience, and their scores were lower. Existing research can also show that such groups are more sensitive. ${ }^{39,40}$ Therefore, hospital managers and policy makers should shift lower-level medical needs to community medical care to disperse the pressure on hospitals and attach importance to personalized services of high-quality medical care. 


\section{Limitation}

The limitations of this study mainly included three points. The first was to use an advanced information technology to enlarge the sample size. Although this survey had successfully obtained a valid sample of 6,480 cases, its size only accounted for $0.02 \%$ of the annual outpatient number of these 16 tertiary hospitals. To obtain more comprehensive and reliable research conclusions, future research could use non-contact methods such as e-mail, WeChat, and SMS to expand the sample size, which could save costs and obtain effective data in real time. Second, the research classified patients according to the departments they visited but did not divide by the type of diseases or the severity of the diseases, which means that the psychological factors and other influencing factors of some patients are difficult to speculate.Third, there was a certain deviation in the survey of pediatric patients. The guardian of the pediatric patients filled in the questionnaire instead, and it makes the results lack a certain degree of accuracy.

\section{Conclusion}

In terms of affecting factors, treatment affected, Environmental sanitation and comfort and other staff's attitude had the lowest satisfaction scores, while the service quality and hospital environment scored lower in the dimensional criteria. The hospital should pay attention to these aspects and improve the current situation to promote outpatients satisfaction. Attention could be paid to these factors in three aspects to improve outpatient satisfaction: for patients, female, and patients with higher education and managerial background. Universal access to medical insurance for outpatients and meet the needs of pediatric and surgical patients and their families could increase the satisfaction. For the hospital, they are the diagnosis and treatment process optimization, efficiency and staff training improvement and environmental embellishment. Government should accelerate the implementation of the policies that have been issued to enhance the enthusiasm of medical staff to practice. For hospital administrators, personalized medical service plans for patients with high expectations should be formulated, and the hospital's humane environment should be emphasized.

\section{Ethical Approval}

The investigation content and plan of this study were approved by Zhejiang Provincial Health Commission. (No:201702) The approval date is: March 15, 2017.All 16 tertiary hospitals had been aware of the investigation content and had agreed to carry out the project. All interviewed patients had been informed about the purpose of the study and given their consent before the start of the investigation. This study was conducted in accordance with the Declaration of Helsinki.

\section{Acknowledgments}

The authors of this study thanked the Zhejiang Provincial Health Commission for their support, the 16 tertiary hospitals for their support, and all the investigators and interviewed patients.

\section{Disclosure}

The authors report no conflicts of interest in this work.

\section{References}

1. Zhang Y, Fang J, Gao W, et al. Treatment satisfaction in Chinese medicine outpatient care: a comparison of patients' and doctors' views. BMC Complement Altern Med. 2019;19(1):300. doi:10.1186/ s12906-019-2729-8

2. Fang J, Liu L, Fang P. What is the most important factor affecting patient satisfaction - a study based on gamma coefficient. Patient Prefer Adherence. 2019;13:515-525.

3. Yu W, Li M, Xue C, et al. Determinants and influencing mechanism of outpatient satisfaction: a survey on tertiary hospitals in the People's Republic of China. Patient Prefer Adherence. 2016;10:601-612.

4. He X, Li L, Bian Y. Satisfaction survey among primary health care outpatients in the backward region: an empirical study from rural Western China. Patient Prefer Adherence. 2018;12:1989-1996.

5. Desta H, Berhe T, Hintsa S. Assessment of patients' satisfaction and associated factors among outpatients received mental health services at public hospitals of Mekelle Town, northern Ethiopia. Int J Ment Health Syst. 2018;12(3):143-150.

6. Lv Y, Xue C, Ge Y, et al. Analysis of factors influencing inpatient and outpatient satisfaction with the Chinese Military Health service. PLoS One. 2016;11(3): 0151234.

7. Chan BJ, Barbosa J, Moinul P, et al. Patient satisfaction with wait times at an emergency ophthalmology on-call service. Can J Ophthalmol. 2018;53(2):110-116.

8. Mazaheri Habibi MR, Abadi FM, Tabesh H, Vakili-Arki H, AbuHanna A, Eslami S. Evaluation of patient satisfaction of the status of appointment scheduling systems in outpatient clinics: identifying patients' needs. J Adv Pharm Technol Res. 2018;9(2):51-55.

9. Semegn S, Alemkere G. Assessment of client satisfaction with pharmacist services at outpatient pharmacy of Tikur Anbessa Specialized Hospital. PLoS One. 2019;14:10.

10. Gejea T, Abadiga M, Hasen T. Maternal satisfaction with delivery services of Government Hospitals in Ambo Town, West Shoa Zone, Oromia Region, Ethiopia, 2020. Patient Prefer Adherence. 2020;22 (14):1225-1235.

11. Donate-Manzanares M, Rodríguez-Cano T, Gómez-Salgado J, et al. Quality of childbirth care in women undergoing labour: satisfaction with care received and how it changes over time. J Clin Med. 2019;8 (4):434.

12. Adhikari M, Paudel NR, Mishra SR, Shrestha A, Upadhyaya DP. Patient satisfaction and its socio-demographic correlates in a tertiary public hospital in Nepal: a cross-sectional study. BMC Health Serv Res. 2021;21(1):135. 
13. Waqaar D, Paul AN, Joel W. The effect of length of hospital stay and patient factors on patient satisfaction in an academic hospital. Orthopedics (Online). 2020;43(6):373-379.

14. Hu L, Ding H, Hu G, Wang Z, Liu S, Liu Y. How perceived quality of care affects outpatient satisfaction in china: a cross-sectional study of 136 tertiary hospitals. Inquiry. 2019;56:46958019895397.

15. Wang X, Chen J, Burström B, Burström K. Exploring pathways to outpatients' satisfaction with health care in Chinese public hospitals in urban and rural areas using patient-reported experiences. Int J Equity Health. 2019;18(1):29.

16. Farzianpour F, Byravan R, Amirian S. Evaluation of patient satisfaction and factors affecting it: a review of the literature. Health. 2015;07(11):1460-1465.

17. Ke L, Chen J, Jia J, et al. Outpatients' satisfaction in the context of 10 years of health-care reform: a cross-sectional study of tertiary hospitals in Shiyan, China. Patient Prefer Adherence. 2020;14:191-202.

18. Jha AK, Tsai TC, Orav EJ. Patient satisfaction and quality of surgical care in US hospitals. Ann Surg. 2014;261(1):2-8.

19. de Lima Lopes J, Cardoso ML, de Souza Alves VL, et al. Satisfação de clientes sobre cuidados de enfermagem no contexto hospitalar Satisfacción de clientes sobre cuidados de enfermería en el contexto hospitalario Outpatient satisfaction with nursing care. Acta Paulista De Enfermagem. 2009;22(2):136-141.

20. Szyca R, Rosiek A, Nowakowska U, Leksowski K. Analysis of factors influencing patient satisfaction with hospital treatment at the surgical department. Pol Przegl Chir. 2012;84(3):136-143.

21. Li M, Huang C, Lu X, Chen S, Zhao P, Lu H. Evaluation of medical staff and patient satisfaction of Chinese hospitals and measures for improvement. Biosci Trends. 2015;9(3):182-189.

22. Daniels KM, Yorlets RR, Flath-Sporn SJ, et al. Patient satisfaction in a pediatric plastic and oral surgery department. $J$ Healthc Manag. 2017;62(3):211-219.

23. Pan J, Liu D, Ali S. Patient dissatisfaction in China: what matters. Soc Sci Med. 2015;143:145-153.

24. Sanford Z, Weltz AS, Zahiri HR, Park A. Demographic-related variables impact subjective experiences of patient wait times and perceived attention afforded in surgical outpatient clinic encounters. $\mathrm{Am}$ J Surg. 2020;219(1):27-32.

25. Wei J, Shen L, Yang HB, et al. Development and validation of a Chinese outpatient satisfaction questionnaire: evidence from 46 public general hospitals and 5151 outpatients. Public Health. 2015;129(11):1523-1529.

26. Zhao N, Wang X, Wu W, et al. Gender differences in quality of life and functional disability for depression outpatients with or without residual symptoms after acute phase treatment in China. J Affect Disord. 2017;219:141-148.
27. Miljanović M, Sindik J, Milunović V, et al. Psychosocial determinants of satisfaction with hospital care in adult patients suffering from advanced cancer. Acta Clin Croat. 2017;56(2):218-226.

28. Chen H, Li M, Wang J, et al. Factors influencing inpatients' satisfaction with hospitalization service in public hospitals in Shanghai, People's Republic of China. Patient Prefer Adherence. 2016;10:469-477.

29. Binsalih SA, Waness AO, Tamim HM, Harakati MS, Al Sayyari AA. Inpatients' care experience and satisfaction study. J Family Community Med. 2011;18(3):111-117.

30. Hu L, Zhou BP, Liu S, Wang Z, Liu Y. Outpatient satisfaction with tertiary hospitals in china: the role of sociodemographic characteristics. Int J Environ Res Public Health. 2019;16(19):3518.

31. Hu L PhD, Ding H BA, Liu S MS, Wang Z MS, Hu G PhD, Liu Y $\mathrm{PhD}$. Influence of patient and hospital characteristics on inpatient satisfaction in China's tertiary hospitals: A cross-sectional study. Health Expect, 2020;23(1):115-124.

32. Goeppel C, Frenz P, Grabenhenrich L, et al. Assessment of universal health coverage for adults aged 50 years or older with chronic illness in six middle-income countries. Bull World Health Organ. 2016;94 (4):276-85C.

33. Yan Z, Wan D, Li L. Patient satisfaction in two Chinese provinces: rural and urban differences. Int J Environ Res Public Health. 2011;23 (4):384-389.

34. Gu D, Yang X, Li X, Liang C, Zhong J, Feng N. Innovating new Rural Cooperative Medical Scheme (NCMS) for better patient satisfaction in Rural China. Int J Environ Res Public Health. 2018;15 (9):2007.

35. Batbaatar E, Dorjdagva J, Luvsannyam A, et al. Determinants of patient satisfaction: a systematic review. Perspect Public Health. 2017;137(2):89-101.

36. Li J, Zhang X, Kuang L, Fu Y, Song Q, Zhao J. Burnout level and job satisfaction in Chinese pediatrics residents: a web-based cross-sectional study. Medicine. 2020;99(8):e19249-e19249.

37. Xu S, Tao L, Huang H, Little J, Huang L. Pediatric nurses' turnover intention and its association with calling in China's Tertiary Hospitals. J Pediatr Nurs. 2020;52:e51-e56.

38. Berhane A, Enquselassie F. Patient expectations and their satisfaction in the context of public hospitals. Patient Prefer Adherence. 2016;10:1919-1928.

39. Li C, Liao C, Meng X, et al. Effective analysis of inpatient satisfaction: the random forest algorithm. Patient Prefer Adherence. 2021;15:691-703.

40. Wudu M. Predictors of adult patient satisfaction with inpatient nursing care in public hospitals of Eastern Amhara Region, Northeastern Ethiopia, 2020. Patient Prefer Adherence. 2021;15:177-185.
Patient Preference and Adherence

\section{Publish your work in this journal}

Patient Preference and Adherence is an international, peer-reviewed, open access journal that focusing on the growing importance of patient preference and adherence throughout the therapeutic continuum. Patient satisfaction, acceptability, quality of life, compliance, persistence and their role in developing new therapeutic modalities and compounds to optimize clinical outcomes for existing disease states are major areas of interest for the journal. This journal has been accepted for indexing on PubMed Central. The manuscript management system is completely online and includes a very quick and fair peer-review system, which is all easy to use. Visit http:// www.dovepress.com/testimonials.php to read real quotes from published authors. 